\title{
pharmACOphore: multiple flexible ligand alignment based on ant colony optimization
}

\author{
Gerhard Hessler $^{1 *}$, Oliver Korb ${ }^{2}$, P Monecke ${ }^{3}$, T Stützle ${ }^{4}$, TE Exner $^{5}$ \\ From 5th German Conference on Cheminformatics: 23. CIC-Workshop \\ Goslar, Germany. 8-10 November 2009
}

Molecular alignment of biologically active compounds is a key technique in ligand-based drug design. Such alignments can be used for similarity-based identification of new compounds by using known active template structures as seeds. Furthermore, alignments allow for the identification of potential pharmacophoric features in a set of chemically divers, biologically active molecules.

Here, pharmACOphore is presented, a new approach for pairwise as well as multiple flexible alignments of ligands based on ant colony optimization (ACO) [1] Translational, rotational and torsional degrees of freedom of all ligand structures are encoded on a pheromone vector (Figure 1). The artificial ant colony uses this representation to mark favourable values for each degree of freedom by depositing a pheromone trail onto the corresponding pheromone vector. The amount of pheromone deposited directly depends on the solution quality, assessed by the scoring function.

The scoring function was parameterized by reproducing reference alignments taken from four different proteins. The performance of the new alignment algorithm will be demonstrated by pairwise alignments obtained for examples from the FlexS data set [2] and by an additional example for multiple flexible alignment.

\section{Author details \\ ${ }^{1}$ Drug Design, Chemical and Analytical Sciences, Sanofi-Aventis Deutschland GmbH, Frankfurt, Germany. ${ }^{2}$ Cambridge, UK. ${ }^{3}$ Frankfurt, Germany. ${ }^{4}$ Brussels, Belgium. ${ }^{5}$ Konstanz, Germany. \\ Published: 4 May 2010 \\ References \\ 1. Dorigo M, Stützle T: Ant Colony Optimization MIT Press, Cambridge, MA, USA 2004 \\ 2. Lemmen C, Lengauer T, Klebe G: FLEXS: A Method for Fast Flexible Ligand Superposition. J Med Chem 1998, 41:4502-4520.}

${ }^{1}$ Drug Design, Chemical and Analytical Sciences, Sanofi-Aventis Deutschland $\mathrm{GmbH}$, Frankfurt, Germany

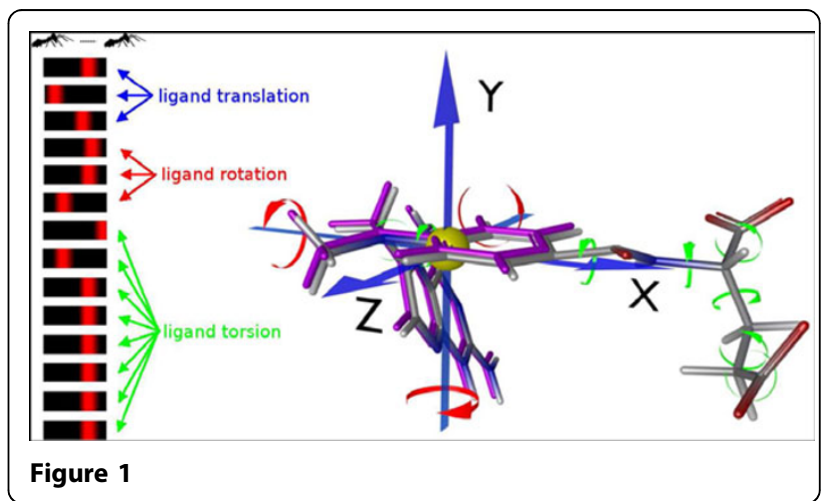

doi:10.1186/1758-2946-2-S1-P17

Cite this article as: Hessler et al:: pharmACOphore: multiple flexible ligand alignment based on ant colony optimization. Journal of Cheminformatics 2010 2(Suppl 1):P17.
Publish with ChemistryCentral and every scientist can read your work free of charge

"Open access provides opportunities to our colleagues in other parts of the globe, by allowing anyone to view the content free of charge." W. Jeffery Hurst, The Hershey Company.

- available free of charge to the entire scientific community

- peer reviewed and published immediately upon acceptance

- cited in PubMed and archived on PubMed Central

- yours - you keep the copyright

Submit your manuscript here:

http://www.chemistrycentral.com/manuscript/

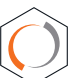

Chemistry Central 